\title{
Situation variation in consumers' media channel consideration
}

Citation for published version (APA):

Wendel, S., \& Dellaert, B. G. C. (2005). Situation variation in consumers' media channel consideration. METEOR, Maastricht University School of Business and Economics. METEOR Research Memorandum No. 006 https://doi.org/10.26481/umamet.2005006

Document status and date:

Published: 01/01/2005

DOI:

10.26481/umamet.2005006

Document Version:

Publisher's PDF, also known as Version of record

\section{Please check the document version of this publication:}

- A submitted manuscript is the version of the article upon submission and before peer-review. There can be important differences between the submitted version and the official published version of record.

People interested in the research are advised to contact the author for the final version of the publication, or visit the DOI to the publisher's website.

- The final author version and the galley proof are versions of the publication after peer review.

- The final published version features the final layout of the paper including the volume, issue and page numbers.

Link to publication

\footnotetext{
General rights rights.

- You may freely distribute the URL identifying the publication in the public portal. please follow below link for the End User Agreement:

www.umlib.nl/taverne-license

Take down policy

If you believe that this document breaches copyright please contact us at:

repository@maastrichtuniversity.nl

providing details and we will investigate your claim.
}

Copyright and moral rights for the publications made accessible in the public portal are retained by the authors and/or other copyright owners and it is a condition of accessing publications that users recognise and abide by the legal requirements associated with these

- Users may download and print one copy of any publication from the public portal for the purpose of private study or research.

- You may not further distribute the material or use it for any profit-making activity or commercial gain

If the publication is distributed under the terms of Article $25 \mathrm{fa}$ of the Dutch Copyright Act, indicated by the "Taverne" license above, 


\title{
Situation Variation in Consumers' Media Channel Consideration
}

\author{
Sonja Wendel and Benedict G.C. Dellaert \\ Department of Marketing \\ Faculty of Economics and Business Administration \\ Maastricht University \\ PO Box 616, 6200 MD Maastricht, The Netherlands \\ Phone: +31 43388 3839, Fax: +31 433884918 \\ email: $\underline{\text { S.Wendel@mw.unimaas.nl and B.Dellaert@mw.unimaas.nl }}$
}

This version, February 2005

\section{Acknowledgments}

The authors thank KLICT: Chain networks, clusters, and ICT for financial support for part of this project; Olga Gommers for valuable research assistance; Theo Arentze, Ko de Ruyter, Frank Engelbart, Gerald Häubl, Eelko Huizingh, Christine Moorman, Fred van Raaij, Hans van Trijp, and George Zinkhan for insightful comments and suggestions; and an anonymous food product manufacturer for its valuable support of this project. 


\title{
Situation Variation in Consumers' Media Channel Consideration
}

\author{
Abstract \\ In this article, the authors investigate consumers' consideration of media channels during \\ different usage situations. They develop a model that explains consumers' media channel \\ consideration as a function of the media channel's perceived benefits. In addition, they \\ hypothesize that the usage situation affects consumers' media channel consideration and \\ that situation-based benefit requirements moderate the effect of the benefits on their \\ channel consideration. The authors test the hypothesized relationships using survey data \\ from 341 consumers regarding their consideration of 12 different media channels used by \\ manufacturers to communicate product information across three product-related usage \\ situations. The results of the analyses support the proposed model structure and confirm \\ the expected relationships among perceived media channel benefits, usage situations, \\ media channel requirements, and consumers' media channel consideration.
}




\section{Introduction}

Recent advances in communication technology such as the Internet have changed managers' and consumers' ideas about how firms and customers should interact (e.g., Haeckel 1998; Watson et al. 2000); increasingly, consumers are viewed as active participants in supply chain value-creation processes (e.g., Wind and Rangaswamy 2001). An important consequence of this new perspective is that it has become more important for firms to provide their consumers with information about their offerings. For example, in the case of online customization (e.g., Dell), consumers must be able to understand the details of many product variants to judge which variant is most suitable for them and provide their made-to-measure specifications (Huffman and Kahn 1998). In the case of food products, consumers need to understand how they can use the manufacturer's product enjoyably and safely.

In turn, manufacturers are faced with new questions about how to communicate with their consumers. First, in the context of specific media channels, how should product information be designed to communicate effectively with consumers? For example, recent research highlights the interactive nature of new media channels such as the Internet, as well as the requirements this places on communication design (Stewart and Pavlou 2002). Second, which media channels should be used to communicate with consumers? Even if product communications are well designed, they may be ineffective if the messages are sent through media channels that consumers do not consider.

We address this second question in the current study. In particular, we analyze consumers' consideration of media channels by investigating which channels they find acceptable. The concept of consideration has received ample attention in consumer choice literature (e.g., Roberts and Lattin 1997), which has shown that, for a brand to be chosen, it first must be included in the consumer's consideration set, which we define as the subset of brands for which a consumer makes an explicit utility comparison or cost-benefit tradeoff 
analysis before making a brand choice (Mehta, Rajiv, and Srinivasan 2003). We propose that the concept of a consideration set can be extended to the field of media channels and investigate how consumers' media channel consideration is related to the communication benefits they perceive these various media channels to possess.

In our analysis, we also investigate the notion that consumers' consideration of media channels depends on the specific usage situation (e.g., Seybold 2001). This phenomenon has been well supported by previous work on the effect of situational variations on consumer preferences for products and services (Srivastava, Leone, and Shocker 1981). We hypothesize that situational differences in consumer preferences exist in consumers' media channel consideration and argue that the usage situation influences which benefits consumers require from a media channel. For example, in some situations, consumers may be more interested in media channels that are fast to use, whereas in others, they may find it more important that the channel provides very detailed information. Specifically, we expect that consumers' media channel consideration will shift according to the usage situation and that this shift is due to differences in the requirements they have for the media channels.

\section{Consumers' Media Channel Consideration}

The starting point for our conceptual model is the notion that media channels provide different benefits to consumers (Gutman 1982). In the context of product consumption, benefits are "the advantages that consumers enjoy from the consumption of products" (Gutman 1982, p. 61). Our focus is on the benefits that consumers enjoy from using alternative media channels, which we describe in terms of the advantages that consumers may perceive these various media channels to have (e.g., informative, time saving).

In theorizing about the formation of consumers' media channel consideration sets (i.e., the set of media channels that a consumer finds acceptable for use), we follow a cost-benefit 
approach (Roberts and Nedungadi 1995). With this approach, consideration set formation occurs as a process in which consumers consider the use of a certain media channel only if the benefits of including this channel in their consideration set exceed their individual threshold of consideration (e.g., Bronnenberg and Vanhonacker 1996). The individual threshold entails the various (cognitive and labor) costs associated with a detailed evaluation of the channel (e.g., Hauser and Wernerfelt 1990). An implicit assumption in this approach is that consumers engage in a relatively active consideration set formation process. In this process, consumers evaluate whether or not to include a media channel in their consideration set based on the benefits they perceive a certain media channel to have. Therefore, we expect that a media channel that provides more benefits is more likely to be included in the consumer's consideration set. In Figure 1, we graphically summarize this relationship, as well as the other hypotheses in our conceptual model.

H1: Media channels that have a greater number of benefits are more likely to be included in the consumer's consideration set.

Other research that has investigated consumer decision processes (e.g., Hoyer and Brown 1990) notes that persons may not always be aware of product or channel benefits or expend the cognitive effort to make benefit comparisons in their decision-making strategy and therefore may rely on simpler heuristics or habit. For example, Swait and Adamowicz (2001) find that consumers simplify their product choice strategies by focusing on the brand's main effects, not on specific product attributes. We expect that such a decision simplification rule may transfer to consumers' media channel consideration, in which case media channel consideration would be based mainly on relatively stable, media channel-specific intercepts and not be affected by media channel benefits. Therefore, we may find that we need to reject 
$\mathrm{H} 1$ in favor of an alternative model of consumers' media channel consideration in which media channel benefits are not actively evaluated.

\section{Situational Variation}

We also address situational differences in consumers' media channel consideration. The influence of the usage situation on consumer preferences for products and services has been well documented in prior research on consumer behavior (Belk 1974, 1975; Srivastava, Alpert, and Shocker 1984). In line with Belk (1974, p. 157), we define a usage situation as "those factors particular to a time and place of observation, which do not follow from personal (intra-individual) and stimulus (choice alternative) attributes, and which have a demonstrable and systematic effect on current behavior."

Previous research, such as that by Ratneshwar and Shocker (1991), has investigated the impact of different usage contexts on consumer consideration sets and shown that consumers consider different products in different usage situations. These findings are in line with those of Warlop and Ratneshwar (1993), who illustrate the importance of the usage context (familiar versus unfamiliar situations) regarding the formation of consideration sets. Also, Desai and Hoyer (2000) explore the effects of two specific usage situations - usage occasion frequency and usage location familiarity — on consideration sets and observe that memorybased consideration sets differed across situations. On the basis of these results, we expect that the usage situation will play a significant role in the context of consumers' media channel consideration. For example, searching for product information after the announcement of a food scare might lead a consumer to consider different media channels than would looking for product information about a new product that just was introduced into the market.

H2: The usage situation affects which media channel a consumer considers. 
A particularly relevant stream of research to explain the mechanism behind this hypothesized situational effect on consumers' media channel consideration is the substitution-in-use (SIU) approach (Ratneshwar and Shocker 1991; Srivastava et al. 1981). A key insight from the SIU approach is that the benefits that consumers require a product to have vary across usage situations (i.e., consumer needs vary across usage situations). Srivastava et al. (1984) argue that consumers look specifically for the benefits that products provide rather than for the products themselves and emphasize the impact of the environment that surrounds the product and consumer. Over time, consumers may group products for consideration on the basis of the "perceived appropriateness of their functional attributes for the intended usage" (Srivastava et al. 1984, p. 32).

This reasoning implies that products convey different benefits to consumers and that these benefits in turn may be demanded in different usage situations. The effect of the situation on consideration is supported by previous research that shows that the usage context helps consumers define the benefits they require from the product's use (e.g., Warlop and Ratneshwar 1993). Ratneshwar and Shocker (1991) build on the knowledge that consumers look for certain benefits when choosing their products to note that products can act as substitutes in a given usage situation if they fulfill the same benefits for which a consumer is searching. Gutman (1982) presents a model for means-end chain analysis that incorporates the usage situation and argues that consumers consider the consequences (which also might be called benefits) according to the requirements of the situation. Thus, in line with Gutman (1982), we expect that consumers' benefit requirements depend on the demands of the situation. Finally, Ratneshwar et al. (1997) argue that product benefits can be more or less salient according to the context of a particular usage situation (situational benefit salience).

Because the SIU approach (Ratneshwar and Shocker 1991; Srivastava et al. 1981), as well as other research on consumer benefit requirements (Gutman 1982; Myers 1976), 
provides evidence that consumer benefit requirements differ across usage situations, we hypothesize that the process by which usage situations affect consideration also operates in the context of media channels and, therefore, that the usage situation has a significant impact on consumers' benefit requirements for media channels. For example, in a usage situation in which a consumer is pressured for time, he or she will look for different media channel benefits to retrieve product information than he or she might in a usage situation whose purpose is to gather product information about DVD players for a future purchase. In the former usage situation, the consumer may require channel benefits such as time saving and ease of use, whereas in the latter, he or she may require channel benefits such as detailed information and trustworthiness.

H3: The usage situation affects which media channel benefits a consumer requires.

Based on the SIU approach, Srivastava et al. (1981) suggest that the use of a product depends on the match between the product's benefits and the requirements of the usage situation. That is, the process by which the usage situation affects product consideration proceeds through the importance that consumers attach to product benefits, and this importance in turn is influenced by whether the consumers require this benefit in a given usage situation (e.g., Ratneshwar and Shocker 1991). In other words, the benefits that a consumer requires moderate the effect of these benefits on product use. Extending this argument to the context of consumers' media channel consideration, we expect that consumers' consideration depends on whether there is a match between the media channel benefits consumers perceive and those they require; the latter, of course, are driven by the usage situation. For example, if a consumer is confronted with a usage situation that involves time pressures (e.g., to retrieve product information after a food scare has been announced), he or she may require a media channel that takes little time to use. If this consumer perceives 
the Internet to be a media channel that saves time, he or she is more likely to consider the Internet in the given usage situation.

H4: The media channel benefits that consumers require moderate the effect of those benefits on media channel consideration.

An alternative to $\mathrm{H} 4$ may be that the usage situation directly moderates the effect of media channel benefits on media channel consideration rather than indirectly through consumers' media channel benefit requirements. For example, if consumers are not able to express or differentiate their benefit requirements for different usage situations, the hypothesized moderating effect of benefit requirements may not occur. Consumer benefit requirements also could be stable for individual consumers and therefore not vary between usage situations, in which case these consumers may perceive the variations in their media channel requirements across usage situations as relatively minor. Therefore, in testing $\mathrm{H} 3$ and H4, we also evaluate an alternative model of consumers' media channel consideration in which we do not include the moderating effect of benefit requirements, and we test directly for the effect of the usage situation on media channel benefit requirements.

\section{Method and Data}

The past decade has witnessed increased consumer awareness of the impact of food product ingredients and food manufacturing technology on human health. For example, Moorman and Matulich (1993) observe that consumers are increasingly sensitive to factors that affect their health. Other studies have shown that, at least in the United States, consumers' awareness of the role of diet and appropriate nutrition in self-medication and disease prevention is growing (e.g., Childs and Poryzees 1997; Sloan 1999). These trends present food manufacturers with increased challenges to communicate effectively with their 
consumers about food products' ingredients, as well as other aspects of their production process.

Data for our project were collected as part of a larger survey conducted in cooperation with such a food product manufacturer. The survey was administered to 453 consumers who were members of a large Internet-based panel of approximately 25,000 members.

Respondents were selected from the panel on the basis of the criterion that they had the responsibility for food purchases in their household. Panel participants were informed about the survey by e-mail, and the survey web link was closed after 453 responses were obtained. ${ }^{1}$ Additional respondents were directed to a page informing them that the survey was closed. Of these 453 respondents, 94 were not presented with questions regarding usage situation, ${ }^{2}$ which gives us a sample of 341 for our analyses that involve usage situation-specific effects.

\section{Measurement approach}

To measure respondents' perceptions of various media channel benefits, usage situation-specific benefit requirements, and media channel considerations, we constructed the survey on the basis of an association pattern technique (APT) approach (Ter Hofstede et al. 1998; Ter Hofstede, Steenkamp, and Wedel 1999). The APT approach originally was developed to study the relationships consumers perceive between different products, product benefits (e.g., low in calories), and their personal objectives (e.g., to be healthy). Unlike qualitative approaches to collecting such data, the APT approach enables us to quantify the relationships between the media channels and their perceived benefits, as well as between the situations and benefits in which we are interested. Furthermore, the questionnaire format of the APT enables us to collect data in an efficient (it is less time consuming than, say, laddering interviews) and relatively less costly manner, because experienced and trained interviewers are not needed. In comparison with more conventional scaling approaches, APT more clearly presents the questions regarding media channel-benefit relationships, uses a 
relatively simple response task (binary choices), and an insightful representation of the structure of interest. Thus, the APT approach is especially suitable for quantitative analyses of large-scale studies of media channel (or product) and benefit relationships.

To achieve our objective of investigating the effect of the usage situation on media channel consideration, we adjusted the APT approach in several ways. We limited ourselves to only the relationship between media channels and perceived benefits. Whereas APT would include a second step to connect these benefits to consumer objectives, we focus solely on the first layer of analysis. We also extend the APT approach to two other types of relationships: the connection between usage situations and media channel benefit requirements (e.g., Srivastava et al. 1981, 1984) and the effects of the usage situation on whether each media channel is considered to obtain product information.

The APT approach requires consumers to use a binary response to indicate, in preconstructed tables, which relationships they believe exist between different variables (e.g., products and benefits). In our study, we presented respondents with three tables (see Appendix A): (1) benefits associated with each media channel (yes, no), (2) benefits a channel should have in a certain usage situation (yes, no), and (3) acceptability of each media channel in the specific usage situation. In a review of different measures of consideration, Brown and Wildt (1992) compare various measures designed to assess the concept of consideration and find only small differences for the semantic variations of the dependent variable of consideration (e.g., "consider acceptable for purchase," "would consider buying," "willing to buy"). We selected the formulation "consider acceptable for use in the specific usage situation" for our study because it is in line with both Brown and Wildt's (1992) findings and previous research on situational effects on consideration (e.g., Srivastava et al. 1984). We created three versions of the second and third table, each of which corresponds to 
one of the three product-related usage situations that we investigate. Respondents were randomly assigned to one of the three versions.

On the basis of three focus groups and discussions with industry experts, we identified 14 relevant media channels and 8 media channel benefits that were most relevant in the context of food product information. Participants in the focus groups were consumers who were responsible for food purchases in their households. The industry experts included marketing managers from the food company with which we worked on this project and consultants working in the food industry. As part of the discussions during the focus groups and meetings with experts, we asked participants to list media channels that consumers could use to obtain food product information. Then, on the basis of this list of media channels, we asked them to discuss the specific benefits that each channel provided and any important differences that existed between them. This qualitative stage of our research provided us with the list of 14 main media channels that consumers might consider and 8 main benefits related to these channels.

Of the 14 media channels in the survey, 3 were Internet-based channels: the manufacturer's website, a third-party website about cooking, and a food information website created by an independent agency. We also included 11 more traditional media channels, including television advertising, television programs, radio advertising, radio programs, magazine advertising, magazine articles, newspaper advertising, newspaper articles, in-store magazines, product labels, and educational brochures. ${ }^{3}$ The 8 media channel benefits included in the study were whether a media channel was trustworthy ("trustworthy"), provided detailed information ("detailed"), took little time to use ("time saving"), was easy to use ("easy"), was tailored to the individual user ("personal"), was exciting and arousing ("stimulating"), was informative ("informative"), and was relaxing to use ("relaxing"). 
During the same focus group interviews and discussions with experts, we also explored and selected product-related usage situations that were appropriate for the context of looking for information about food products. A common characteristic of these scenarios was that they described relatively specific usage situations to which consumers could easily relate. The following three hypothetical usage situations were identified: (1) a food scare in which an ingredient in one of the manufacturer's food products was contaminated, (2) a new product introduction in which the consumer is interested, and (3) a search for a recipe so the consumer can prepare a meal that includes one of the manufacturer's food products.

\section{Sample characteristics}

The sociodemographics of the sample were diverse, with a slight emphasis on more highly educated men. Respondents' ages varied as follows: 16-24 years 14.1\%, 25-34 years $31.8 \%, 35-49$ years $38.2 \%, 50-64$ years $14.3 \%$, and 65 years or older $1.5 \%$. The main observed education levels were as follows: university master's level $18.5 \%$, university bachelor's level $41.7 \%$, and professional education or other type of education $39.8 \%$. The gender distribution was $44.8 \%$ women and $55.2 \%$ men. Of the respondents, $21.8 \%$ lived alone, and the rest lived in households of more than one person; a total of $39.5 \%$ lived in households that included children under 17 years of age.

\section{Analysis and econometric model}

To model and test the impact of the perceived media benefits, generic usage situation effects, and usage situation-specific benefit requirements on consumers' media channel considerations (H1, H2, and H4), we formulated a random coefficient binary logit model. Although prior research has modeled the impact of media communications on consumer behavior and its managerial implications (e.g., Lodish et al. 1995), surprisingly few models 
address consumers' perspectives on media channels. We propose a model that is largely consistent with the type of analysis conducted with APT data (e.g., Ter Hofstede et al. 1998) and in line with previous models of consideration developed by Andrews and Srinivasan (1995) and Bronnenberg and Vanhonacker (1996), who model the probability of considering an alternative as the probability that the alternative's utility exceeds the subject's threshold of consideration.

In our analysis, we model the probability of consideration of a media channel $c$ by a person $i$ in usage situation $s(P(\operatorname{consider}(c, s, i)))$ as a function of the benefits the person perceives of that channel, a usage situation-specific constant, and the benefits the person requires in that usage situation. To allow for heterogeneity in consumers' responses to usage situations and their valuations of the perceived benefits, we use a random coefficient specification (e.g., Train 2003). We express the probability of consideration as follows:

$$
P(\text { consider }(c, s, i))=P\left(B_{c s i}>T_{c s i}\right)
$$

where $B_{c s i}$ is consumer $i$ 's $(i \in I)$ latent evaluation of using a specific media channel $c(c \in C)$ in a specific usage situation $s\left(s \in S\right.$ ) to obtain product information, and $T_{c s i}$ is that consumer's latent threshold for consideration. We then express $B_{c s i}$ as follows:

$$
\begin{gathered}
B_{c s i}=\alpha_{c s i}+\boldsymbol{\beta}_{\mathbf{s i}} \mathbf{X}_{\mathrm{csi}}+\varepsilon_{c s i}, \\
\alpha_{c s i}=\alpha_{c}+\delta_{c s}+v_{i}, \text { and } \\
\boldsymbol{\beta}_{\mathbf{s i}}=\boldsymbol{\beta}+\gamma \mathbf{R}_{\mathrm{si}}+\boldsymbol{\eta}_{\mathbf{i}},
\end{gathered}
$$

where $\alpha_{c s i}$ is the media channel intercept that is consumer and usage situation-specific, $\mathbf{X}_{\mathbf{c s i}}$ is a vector of person i's perceived benefits of using channel $c$ in usage situation $s, \beta_{\mathbf{s i}}$ is a vector of the consumer- and usage situation-specific parameters for the effects of perceived channel benefits on channel evaluation, and $\varepsilon_{c s i}$ is an error component that captures e.g., measurement errors on the part of the researcher. 
In addition, we express the media channel intercept $\alpha_{c s i}$ as a random coefficient with a media channel mean $\alpha_{c}$, a situation-specific media channel effect $\delta_{c s}$, and an error component $v_{i}$. We express the benefit parameter $\beta_{\mathbf{s i}}$ as a random coefficient vector that is a function of a vector of means $\beta$, a vector of a consumer's required benefits $\mathbf{R}_{\mathbf{s i}}$ with parameter $\gamma,{ }^{4}$ and a vector of error components $\eta_{\mathrm{i}}$. We assume that all errors in the random coefficient expressions are independently normal distributed but with different variances.

The consideration threshold can be expressed as

$$
T_{c s i}=\alpha_{i}^{T}+\varepsilon_{c s i}^{T}
$$

where $\alpha_{i}^{T}$ is the consumer-specific threshold intercept, and $\varepsilon_{c s i}^{T}$ is the related error component. To obtain the random coefficient binary logit model, we normalize $\alpha_{i}^{T}$ to 0 and assume that the error terms $\varepsilon_{c s i}$ and $\varepsilon_{c s i}^{T}$ are independently and identically Gumbel distributed.

To test the effect of the usage situation on consumers' media channel benefit requirements (H3), we conduct one further analysis in which the dependent variables are consumers' responses regarding whether they believe each media channel should have different benefits in a given usage situation. We estimate a random coefficient binary logistic regression model with the dependent variable $\mathbf{R}_{\mathbf{s i}}$, the vector of person $i$ 's media channel benefit requirements in usage situation $s$, and the following independent variables: a situation-specific random coefficient intercept $\alpha_{s i}^{R}$ that is constant for the subject and for all benefits, a vector of dummy variables for each media channel benefit $\mathbf{X}_{\mathbf{m}}$ with the parameter $\boldsymbol{\eta}$, and the interaction of this vector with the vector of usage situation dummies $\mathbf{X}_{\mathbf{s}}$ with parameter $\boldsymbol{\theta}$. If these interactions are significant, they support the hypothesis that benefit requirements differ across usage situations (H3). We again assume that all error terms $\varepsilon_{s i}^{R}$ 
are independently and identically Gumbel distributed to obtain the binary logit model. The situation-specific intercept $\alpha_{s i}^{R}$ is expressed as a random coefficient with mean $\alpha_{s}^{R}$ and a normally distributed error component $v_{i}^{R}$.

$$
\begin{gathered}
\mathbf{R}_{\mathbf{s i}}=\alpha_{s i}^{R}+\boldsymbol{\eta} \mathbf{X}_{\mathbf{m}}+\boldsymbol{\theta} \mathbf{X}_{\mathbf{s}} \mathbf{X}_{\mathbf{m}}+\boldsymbol{\varepsilon}_{\mathbf{s i}}^{\mathbf{R}}, \text { and } \\
\alpha_{s i}^{R}=\alpha_{s}^{R}+v_{i}^{R} .
\end{gathered}
$$

\section{Results}

\section{Media channel consideration model}

We hypothesized that a greater number of media channel benefits increases the probability that the media channel will be included in the consumer consideration set $(\mathrm{H} 1)$, that different media channels may be considered in different usage situations $(\mathrm{H} 2)$, and that consumers' media channel benefit requirements moderate the effect of these media channel benefits on media channel consideration by increasing their impact (H4). Testing these hypothesized relationships requires that we estimate the conceptualized model (Equations 1, 2, and 3), which captures consumers' media channel consideration as a joint function of their perceptions of the media channel benefits, usage situation, and required benefits. We present these results in Table 1.

The model results support $\mathrm{H} 1$; most media channel benefits have a significant and positive effect on media channel consideration. We observe significant positive results at the 0.05 level for all media channel benefits except "trustworthy" and "informative." This outcome also reveals that consumers do not rely solely on channel-specific constants, as would be the case if the consumers used decision heuristics to avoid effort (e.g., Swait and Adamowicz 2001). 
We also find significant differences in media channel intercepts depending on the usage situation (H2). In addition, the interaction of consumers' required media channel benefits with their perceived media channel benefits has a significant effect on consumer media channel consideration (H4), as we report in Table 1. Again, the results support the hypothesized relationships. We find significant positive results at the 0.05 level for the media channel benefits "trustworthy," "easy," "stimulating," and "informative."

These latter findings suggest that though the effects of perceived benefits and benefit requirements are significant in the model, they do not explain all the situational variation in consumers' media channel consideration; therefore, usage constants also are required. Furthermore, the results of the random coefficient estimates indicate significant coefficient heterogeneity across consumers' evaluations of the perceived media channel benefits, as well as across the media channel intercepts.

To test the hypothesized model further, we compare its fit with an alternative model that excludes the proposed interaction effects of benefit requirements (i.e., the effect of $\mathbf{R}$ was dropped). This model would be appropriate if consumers did not take into account their benefit requirements when they considered different media channels. The result, obtained through a log-likelihood ratio test (i.e., a $\chi^{2}$ test of $-2 \times$ difference in log-likelihood at 7 degrees of freedom), shows strong support for the model with interactions. The log-likelihood values of the models with and without interactions are -2275.3 and -2289.0 , respectively $(p<$ $0.001)$.

To test H3, we estimated the model described by Equation 4 so that we could capture the dependency of consumers' media channel benefit requirements on the usage situation. We present the results in Table 2, which show that consumers' required media channel benefits differ significantly according to the usage situation. In the case of a food scare, we observe significant differences from the average at the 0.05 significance level for almost all required 
benefits except "easy" and "stimulating." Furthermore, we find significant effects at the 0.05 level for a new product introduction for the benefits "trustworthy," "detailed," and “informative."

To test for the collective effect of all situation-based interactions, we also compared the model that includes these interactions (H3) with a model without interactions. At 14 degrees of freedom, the difference is significant in a $\chi^{2}$ test $(p<0.001)$, in support of our proposed model.

\section{Further analyses}

Although our model of media channel consideration is well supported by academic literature and our empirical results, we also compared it with two rival models that have simpler structures. More specifically, we compared it with (1) a random coefficient model that does not include situational effects (i.e., $\alpha_{c s i}$ is fixed across usage situations and the effect of $\mathbf{R}$ is dropped) and (2) a null model with only a random coefficient intercept. To compare the models, we used log-likelihood ratio tests. The likelihood values were significantly different from one another and from the proposed model structure at the .001 level, which indicates strong support for our model.

We also evaluated the possibility that our results reflect common method effects. First, we consider the effects of the usage situation on consideration and requirements. In this case, there is no ground for a common method bias because we manipulated the situations experimentally rather than according to responses by our subjects (Podsakoff et al. 2003). Second, we evaluate the effects of the reported benefits and requirements on consideration, for which common method bias is a concern. Following Podsakoff et al. (2003), we classified our data collection as a "situation 7" case in which the predictor and criterion variables are not measured in different contexts and the source of the common method bias cannot be 
identified. The suggested response to such a case is twofold. First, in terms of data collection, we must separate the two types of responses as much as possible. We largely followed this requirement in our survey, in which we presented respondents with separate response tables for perceived benefits, required benefits by situation, and media channel consideration by situation. Second, Lindell and Whitney (2001) suggest that the relative impact of the common method bias can be evaluated by calculating the lowest common correlation across all pairs of variables and subtracting it from the total correlation between each pair of variables. In our case, because we deal with binary responses, we calculate the corresponding $\Phi$ correlations. We find that the pattern of correlations is not significantly affected when we correct for the common correlation between all pairs (a technical appendix that details these results is available from the authors on request). Therefore, we conclude that common method bias is not a concern in our analysis.

\section{Discussion}

\section{Conclusions}

This study focuses on consumers' consideration of media channels. We develop a theoretical model to describe the effect of media channel benefits on consumers' media channel consideration and how this effect is influenced by the usage situation. Our findings not only support the hypothesized role of channel benefits in consumers' media channel consideration but also demonstrate that the usage situation is an influential contingency factor for consumers' media channel consideration. These results also indicate that the concept of consideration is useful for investigating consumers' media channel use in the field of manufacturer-to-consumer communications. Furthermore, situational effects prove highly important for analyzing consumers' media channel consideration. 
More specifically, we find support for the hypothesis that a greater number of media channel benefits increases the probability that the media channel will be included in the consumer's consideration set (H1). The results also provide support for the moderating effect of the usage situation (H2) and consumers' benefit requirements (H4) through the significant interaction effect of perceived and required media channel benefits. Finally, we investigated the role of the usage situation as a driver of consumers' required media channel benefits $(\mathrm{H} 3)$. The results reveal that some benefits are required only in certain situations. For example, in the case of a food scare, "easy" and "stimulating" benefits are not important to consumers, whereas in the case of a new product introduction, benefits such as "time saving," "easy," "personal," and "stimulating" were unimportant. This result illustrates that consumers' required benefits depend on the usage situation.

\section{Theoretical implications}

The main implications of our findings for theory are twofold. First, we find support for the idea that we can transfer the notion of consumers engaging in relatively active consideration set formation from product evaluation to media channel evaluation, at least in the usage situations that we investigated. This finding provides opportunities for further research on, for example, utility-based models of media channel consideration and choice, similar to those used in the product choice literature (e.g., Roberts and Lattin 1997).

Second, our results provide empirical support for the SIU approach, particularly the suggestion by Srivastava et al. (1981) that the use of a product or service depends on the match between its benefits and the requirements demanded by the usage situation. Although this mechanism has been described previously, little empirical evidence exists to support the moderating role of usage situation-specific benefit requirements on the effect of benefits on 
choice or consideration. Our results show that this moderating effect occurs and generalize the SIU approach from the context of product choice to that of media channel consideration.

Methodologically, our results indicate that an APT approach (Ter Hofstede et al. 1999) can be applied successfully to measure respondents' perceived media channel benefits, required benefits according to the situation, and media channel consideration. Because APT was developed specifically as a quantitative method to measure means-end chain relationships, it also is appropriate for investigating the linkages between attributes and consequences in consumers' decision structures. In our study, we extended this application to a similar decision structure, namely, to link media channels to consumers' benefits. We find that APT enabled us to measure the relationship between media channels and benefits, between situations and media channel consideration, and between situations and requirements in a structured manner. These relationships can be presented to the respondent as a sequence of matrices that connect, for example, the link between media channels and benefits in a relatively simple but meaningful fashion.

\section{Managerial implications}

A main implication of our study is that marketing managers must understand not only how consumers use media channels but also which media channels they consider. Media channel benefits are important to consumers, and this importance varies across usage situations. For example, in some usage situations, consumers may be time sensitive and prefer a media channel that saves them time, whereas in others, they may focus on those media channels that offer better information quality.

Developing an understanding of consumers' media channel consideration can help managers select the different media channels through which they communicate different types of messages to consumers and reach consumers in different usage situations. For 
example, independent websites are regarded as very trustworthy and therefore represent a good media channel to provide consumers with information in case of a food scare but not one to provide them with recipe suggestions, in which case they may find ease of use a more important benefit. Using the media channels that are most likely to be considered by consumers in specific usage situations to communicate the appropriate information also may reduce consumer information overload, because there will a closer match between the media channel benefits that the consumer wants and the managerial use of that media channel.

\section{Limitations and directions for further research}

In this study, we included media channels and benefits on the basis of qualitative research and experts' judgments. This approach provides a relatively close fit with the respondents' vocabulary and considerations in the context in which we conducted our research (food products). However, other channels and benefits could be considered, such as communities, chat rooms, or discussion forums, to further our understanding of this media channel as a possible product information source (e.g., Ratchford, Talukdar, and Lee 2001; Zinkhan et al. 2003). Although the investigated benefits are largely consistent with previous research, our approach required that we rephrase or omit certain characteristics. For example, consumers' evaluation of the availability of a media channel for obtaining product information may be a combination of their assessment of the ease of access and the specific information to be obtained from that media channel. Therefore, the characteristic "available" is most likely captured in our study by the two media channel benefits "easy" and "time saving." Similarly, the potential media channel benefit of being "nonintrusive" likely was captured in part by the benefits "trustworthy," "detailed," "personal," and "informative."

We investigated product-related usage situations that also were generated through qualitative research. These usage situations all relate to one situational dimension: the task 
definition (Belk 1975), though four other dimensions of situational influence exist (physical and social surroundings, temporal perspective, and antecedent state). An operationalization with five dimensions appears applicable to our research context, and it would be worthwhile to investigate the effect of those dimensions we did not manipulate. Another common characteristic of the usage situations we used was that, to the respondents in the sample (mainly persons responsible for grocery shopping in their household), the usage situations may have represented relatively high-involvement situations. Perhaps even stronger variations in consumer benefit requirements would be observed if such high-involvement usage situations were compared with low-involvement usage situations. In low-involvement usage situations, the overall role of benefits in media channel considerations may be lower than those we found.

During the focus groups and discussions with industry experts, we encouraged respondents to add additional media channels and/or benefits that might relate to previous questions in the interview to ensure that all relevant benefits and channels were captured. However, we cannot rule out the possibility of an order effect due to this elicitation process. Similarly, given the existing structure of the APT data, the possibility arises that because respondents first mentioned benefits, followed by the media channel they would consider, they may have experienced a heightened awareness of different media channels' benefits. This possible ordering effect in the APT approach should be tested in further research.

Consumer media channel benefits other than those that we used also might be important, such as the need for control or the comprehensiveness of the information. It is worth noting that we took a rather general perspective on media channel benefits, in which we did not distinguish between different information provided across channels but rather used consumers' overall evaluation of each channel to reflect the combination of the medium's delivery and the content it offers. In addition, it is difficult to separate these two components 
for the benefits consumers reported. For example, "trustworthy" and "detailed" relate to both the channel and its content. Therefore, we integrated the two, but it would be worthwhile to disentangle the relative roles of content and delivery.

Finally, additional research on multimedia channel use might investigate the interaction of information and purchase channels. One possible avenue might explore when consumers choose the same or different channels to obtain product information and then purchase a product (e.g., in an Internet context). This question is relevant because consumers may obtain their product information through one channel (e.g., retail stores) and then bargain for a good purchase deal using another channel (e.g., the Internet). 


\section{References}

Andrews, Rick L. and T.C. Srinivasan. 1995. "Studying Consideration Effects in Empirical Choice Models Using Scanner Panel Data.” Journal of Marketing Research 32 (February): 30-41.

Belk, Russel W. 1974. “An Exploratory Assessment of Situational Effects in Buyer Behavior.” Journal of Marketing Research 11 (May): 156-163.

Belk, Russel W. 1975. "Situational Variables and Consumer Behavior." Journal of Consumer Research 2 (December): 157-164.

Bronnenberg, Bart J. and Wilfried R. Vanhonacker. 1996. "Limited Choice Sets, Local Price Response, and Implied Measures of Price Competition.” Journal of Marketing Research 33 (May): 163-173.

Brown, Juanita J. and Albert R. Wildt. 1992. “Consideration Set Measurement.” Journal of the Academy of Marketing Science 20 (3): 235-243.

Childs, Nancy M. and Gregg H. Poryzees. 1997. "Foods that Help Prevent Disease:

Consumer Attitudes and Public Policy Implications.” Journal of Consumer Marketing 14 (6): 433-447.

Desai, Kalpesh K. and Wayne D. Hoyer. 2000. "Descriptive Characteristics of MemoryBased Consideration Sets: Influence of Usage Occasion Frequency and Usage Location Familiarity.” Journal of Consumer Research 27 (December): 309-323.

Gutman, Jonathan. 1982. “A Means-End Model Based on Consumer Categorization Processes.” Journal of Marketing 46 (Spring): 60-72.

Haeckel, Stephan H. 1998. “About the Nature and Future of Interactive Marketing.” Journal of Interactive Marketing 12 (1): 63-72.

Hauser, John R. and Birger Wernerfelt. 1990. “An Evaluation Cost Model of Consideration Sets.” Journal of Consumer Research 16 (4): 393-408. 
Hoyer, Wayne D. and Steven P. Brown. 1990. "Effects of Brand Awareness on Choice for a Common, Repeat-Purchase Product.” Journal of Consumer Research 17 (September): $141-148$.

Huffman, Cynthia and Barbara E. Kahn. 1998. "Variety for Sale: Mass Customization or Mass Confusion.” Journal of Retailing 74 (4): 491-514.

Lindell, Michael K. and David J. Whitney. 2001. "Accounting for Common Method Variance in Cross-Sectional Research Designs." Journal of Applied Psychology 86 (1): 114121.

Lodish, Leonard M., Magid Abraham, Stuart Kalmenson, Jeanne Livelsberger, Beth Lubetkin, Bruce Richardson, and Mary Ellen Stevens. 1995. "How T.V. Advertising Works: A Meta-Analysis of 389 Real World Split Cable T.V. Advertising Experiments.” Journal of Marketing Research 32 (May): 125-139.

Mehta, Nitin, Surendra Rajiv, and Kannan Srinivasan. 2003. "Price Uncertainty and Consumer Search: A Structural Model of Consumer Consideration Set Formation." Marketing Science 22 (1): 58-84.

Moorman, Christine and Erika Matulich. 1993. “A Model of Consumers' Preventive Health Behaviors: The Role of Health Motivation and Health Ability." Journal of Consumer Research 20 (September): 208-228.

Myers, James H. 1976. "Benefit Structure Analysis: A New Tool for Product Planning." Journal of Marketing 40 (October): 23-32.

Podsakoff, Philip M., Scott B. MacKenzie, Jeong-Yeon Lee, and Nathan P. Podsakoff. 2003. "Common Method Biases in Behavior Research: A Critical Review of the Literature and Recommended Remedies.” Journal of Applied Psychology 88 (5): 879-903.

Ratchford, Brian T., Debabrata Talukdar, and Myung-soo Lee. 2001. “A Model of Consumer Choice of the Internet as an Information Source.” International Journal of Electronic Commerce 5 (Spring): 7-21. 
Ratneshwar, S. and Allan D. Shocker. 1991. "Situations in Use and the Role of Usage Context in Production Category Structures.” Journal of Marketing Research 28 (August): 281-295.

Ratneshwar, S., Luk Warlop, David G. Mick, and Gail Seeger. 1997. "Benefit Salience and Consumers' Selective Attention to Product Features." International Journal of Research in Marketing 14 (3): 245-259.

Roberts, John R. and James M. Lattin. 1997. “Consideration: Review of Research and Prospects for Future Insights.” Journal of Marketing Research 34 (August): 406-413. Roberts, John R. and Prakash Nedungadi. 1995. "Studying Consideration in the Consumer Decision Process: Progress and Challenges." International Journal of Research in Marketing 12 (1): 3-7.

Seybold, Patricia B. 2001. "Get Inside the Lives of your Customers.” Harvard Business Review 79 (5): 80-90.

Sloan, Elizabeth A. 1999. "Top Ten Trends to Watch and Work on for the Millennium." Food Technology 53 (8): 40-60.

Srivastava, Rajendra K., Mark L. Alpert, and Allan D. Shocker. 1984. “A Customer-Oriented Approach for Determining Market Structures.” Journal of Marketing 48 (Spring): 3245.

Srivastava, Rajendra K., Robert P. Leone, and Allan D. Shocker. 1981. "Market Structure Analysis: Hierarchical Clustering of Products based on Substitution-In-Use.” Journal of Marketing 45 (Summer): 38-48.

Stewart, David W. and Paul A. Pavlou. 2002. "From Consumer Response to Active Consumer: Measuring the Effectiveness of Interactive Media." Journal of the Academy of Marketing Science 30 (4): 376-396. 
Swait, Joffre and Wiktor Adamowicz. 2001. "The Influence of Task Complexity on Consumer Choice: A Latent Class Model of Decision Strategy Switching.” Journal of Consumer Research 28 (June): 135-148.

Ter Hofstede, Frenkel, Anke Audenaert, Jan-Benedict E.M. Steenkamp, and Michel Wedel. 1998. “An Investigation into the Association Pattern Technique as a Quantitative Approach to Measuring Means-End Analysis." International Journal of Research in Marketing 15 (1): 37-50.

Ter Hofstede, Frenkel, Jan-Benedict E.M. Steenkamp, and Michel Wedel. 1999.

“International Market Segmentation Based on Consumer-Product Relations.” Journal of Marketing Research 36 (February): 1-17.

Train, Kenneth E. 2003. Discrete Choice Methods with Simulation. Cambridge, UK:

Cambridge University Press.

Warlop, Luk and S. Ratneshwar. 1993. "The Role of Usage Context in Consumer Choice: A Problem Solving Perspective.” Advances in Consumer Research 20 (1): 377-382.

Watson, Richard T., Pierre Berthon, Leyland F. Pitt, and George M. Zinkhan. 2000.

Electronic Commerce: The Strategic Perspective. Fort Worth, TX: The Dryden Press. Wind, Jerry and Arvind Rangaswamy. 2001. "Customerization: The Next Revolution in Mass Customization.” Journal of Interactive Marketing 15 (1): 13-32.

Zinkhan, George M., Hyokjin Kwak, Michelle Morrison, and Cara O. Peters. 2003. "WebBased Chatting: Consumer Communication in Cyberspace.” Journal of Consumer Psychology 13 (1\&2): 17-27. 
TABLE 1

Estimates of Random Coefficient Binary Logit Model $(n=341)$

Intercept

$-1.02(.08)$

Perceived Benefits

\begin{tabular}{|c|c|c|c|}
\hline \multicolumn{2}{|l|}{ Perceived Benefits } & \multicolumn{2}{|c|}{ Interaction of Required and Perceived Benefits } \\
\hline Trustworthy & $-.02(.15)$ & Trustworthy & $.43(.16)^{*}$ \\
\hline Detailed & $.32(.13)^{*}$ & Detailed & $.20(.14)$ \\
\hline Time saving & $.62(.10)^{*}$ & Time saving & $.07(.16)$ \\
\hline Easy & $.40(.08)^{*}$ & Easy & $.29(.10)^{*}$ \\
\hline Personal & $.77(.10)^{*}$ & Personal & $-.04(.22)$ \\
\hline Stimulating & $.29(.10)^{*}$ & Stimulating & $.54(.18)^{*}$ \\
\hline Informative & $-.01(.10)$ & Informative & $.96(.10)^{*}$ \\
\hline \multicolumn{2}{|c|}{ Media Channel Intercepts (mean) } & & \\
\hline Manufacturer website & $-.05(.15)$ & & \\
\hline Cooking website & $.62(.15)^{*}$ & & \\
\hline Independent nutrition website & $-.67(.16)^{*}$ & & \\
\hline Radio program & $-3.10(.30)^{*}$ & & \\
\hline Magazine advertisement & $-1.15(.19)^{*}$ & & \\
\hline Magazine article & $.62(.16)^{*}$ & & \\
\hline Newspaper advertisement & $-3.69(.32)^{*}$ & & \\
\hline Newspaper article & $-1.17(.16)^{*}$ & & \\
\hline Store magazine & $1.04(.16)^{*}$ & & \\
\hline Label & $-.05(.18)$ & & \\
\hline Brochure & $-.85(.15)^{*}$ & & \\
\hline \multicolumn{2}{|c|}{ Media Channel Intercepts (food scare-specific) } & \multicolumn{2}{|c|}{$\begin{array}{l}\text { Media Channel Intercepts (new product- } \\
\text { specific) }\end{array}$} \\
\hline Manufacturer website & $.11(.19)$ & Manufacturer Website & $.13(.18)$ \\
\hline Cooking website & $-2.18(.22)^{*}$ & Cooking Website & $-2.20(.20)^{*}$ \\
\hline Independent nutrition website & $1.27(.20)^{*}$ & $\begin{array}{l}\text { Independent nutrition } \\
\text { website }\end{array}$ & $-.46(.21)^{*}$ \\
\hline Radio program & $4.04(.32)^{*}$ & Radio program & $.41(.36)$ \\
\hline Magazine advertisement & $-.69(.25)^{*}$ & Magazine advertisement & $2.09(.23)^{*}$ \\
\hline Magazine article & $-1.31(.22)^{*}$ & Magazine article & $-1.43(.20)^{*}$ \\
\hline Newspaper advertisement & $3.60(.36)^{*}$ & Newspaper advertisement & $3.77(.35)^{*}$ \\
\hline Newspaper article & $2.69(.22)^{*}$ & Newspaper article & $-.34(.21)$ \\
\hline Store magazine & $-3.40(.24)^{*}$ & Store magazine & $-.55(.20)^{*}$ \\
\hline Label & $-1.11(.25)^{*}$ & Label & $-.24(.23)$ \\
\hline Brochure & $1.32(.20)^{*}$ & Brochure & $.54(.19)^{*}$ \\
\hline
\end{tabular}


TABLE 1 - continued

Estimates of Standard Deviations of Random Coefficients

\begin{tabular}{lr|lr}
\hline \multicolumn{2}{l}{ Benefits (Standard Deviation) } & \multicolumn{2}{l}{ Media Channel Intercepts (Standard Deviation) } \\
\hline Trustworthy & $.78(.06)^{*}$ & Manufacturer website & $.07(.09)$ \\
Detailed & $1.21(.05)^{*}$ & Cooking website & $.05(.10)$ \\
Time saving & $1.10(.09)^{*}$ & Independent nutrition website & $.03(.10)$ \\
Easy & $.23(.05)^{*}$ & Radio program & $.56(.13)^{*}$ \\
Personal & $.32(.10)^{*}$ & Magazine advertisement & $1.56(.13)^{*}$ \\
Stimulating & $1.01(.09)^{*}$ & Magazine article & $.97(.10)^{*}$ \\
Informative & $.72(.04)^{*}$ & Newspaper advertisement & $2.66(.20)^{*}$ \\
& & Newspaper article & $.03(.10)$ \\
& & Store magazine & $.81(.11)^{*}$ \\
& & Label & $2.16(.15)^{*}$ \\
\end{tabular}

*Significant difference at $p<.05$. The benefit "relaxing" and the situation "search for a recipe" were used as the base levels in the dummy coding of benefits and situations. 
TABLE 2

Required Property Estimates of Random Coefficient Binary Logit Model $(n=341)$

Situation-Specific Intercepts

Estimates of Standard Deviations of Random Coefficients

\begin{tabular}{ll|lr}
\hline Food scare & $-5.16(.61)^{*}$ & Food scare & $1.08(.09)^{*}$ \\
New product & $-2.40(.19)^{*}$ & New product & $.55(.06)^{*}$ \\
Recipe search & $-1.48(.14)^{*}$ & Recipe search & $.50(.05)^{*}$
\end{tabular}

Required Benefits (mean)

\begin{tabular}{|c|c|c|c|}
\hline Trustworthy & $1.85(.18)^{*}$ & & \\
\hline Detailed & $2.25(.18)^{*}$ & \multirow{7}{*}{\multicolumn{2}{|c|}{ Required Benefits (new product) }} \\
\hline Time saving & $.90(.17)^{*}$ & & \\
\hline Easy & $2.41(.18)^{*}$ & & \\
\hline Personal & $-.56(.22)^{*}$ & & \\
\hline Stimulating & $.66(.19)^{*}$ & & \\
\hline Informative & $1.87(.18)^{*}$ & & \\
\hline Required Benefits (food scare) & & & \\
\hline Trustworthy & $6.39(.69)^{*}$ & Trustworthy & $1.94(.31)^{*}$ \\
\hline Detailed & $4.72(.66)^{*}$ & Detailed & $1.03(.29)^{*}$ \\
\hline Time saving & $1.86(.65)^{*}$ & Time saving & $-.13(.29)$ \\
\hline Easy & $1.03(.64)$ & Easy & $.31(.29)$ \\
\hline Personal & $2.96(.72)^{*}$ & Personal & $.46(.36)$ \\
\hline Stimulating & $.06(.74)$ & Stimulating & $.49(.31)$ \\
\hline Informative & $5.34(.67)^{*}$ & Informative & $2.22(.30)^{*}$ \\
\hline
\end{tabular}

*Significant difference at $p<.05$. 
FIGURE 1

Conceptual Model of Consumers' Media Channel Consideration*

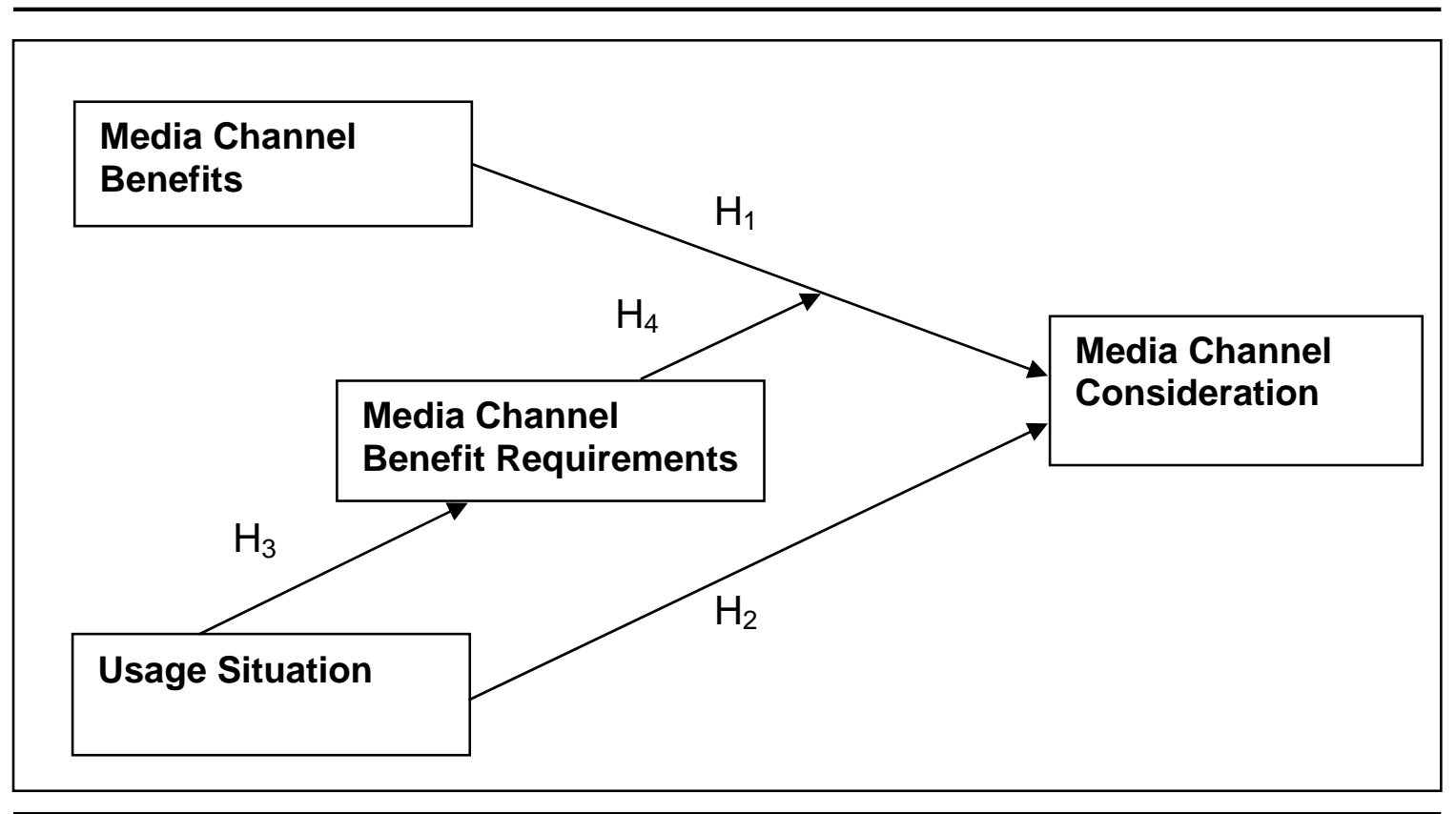

*Media channel benefit requirements are hypothesized to depend on the consumers' usage situation (H3) and to moderate the effect of perceived media channel benefits on media channel consideration (H4). 


\section{Notes}

1. This cut off was based on budget constraints set by the firm with which we worked in this study.

2. Subjects received questions that addressed additional research issues raised by our partner firm and that were not relevant for the objectives of our study.

3. In our analysis, we eliminated the media channels television advertising and radio advertising because they are relatively difficult for consumers to access on demand and the most obtrusive. These two properties may constrain consumers who wish to obtain product information and therefore make these media channels less suitable for our analysis. We thank two reviewers for bringing this issue to our attention. Our results did not change substantively after we eliminated these two media channels.

4. These estimates pick up the additional impact of a benefit on consideration when it is required versus when it is not required by the respondent. Therefore, even if the estimates $\beta$ of the main effects of different benefits are not significant, the $\gamma$ estimates may be significant and meaningful when the benefits are required. 
APPENDIX A

Summary of questionnaire

Please indicate in the table below what characteristics you recognize in the different media channels (when looking for product information on vegetables). Please indicate this one row at a time and feel free to mark as many combinations as you want.

Perceived Benefit

\begin{tabular}{|c|c|c|c|c|c|c|c|c|}
\hline & $\begin{array}{l}\text { Trust- } \\
\text { worthy }\end{array}$ & Detailed & $\begin{array}{l}\begin{array}{l}\text { Time } \\
\text { saving }\end{array} \\
\end{array}$ & Easy & Personal & Stimulating & $\begin{array}{l}\text { Informat } \\
\text { ive }\end{array}$ & Relaxing \\
\hline $\begin{array}{l}\text { Website } \\
\text { Manufacturer }\end{array}$ & $\square$ & $\square$ & $\square$ & $\square$ & $\square$ & $\square$ & $\square$ & $\square$ \\
\hline $\begin{array}{l}\text { Website } \\
\text { Cooking }\end{array}$ & $\square$ & $\square$ & $\square$ & $\square$ & $\square$ & $\square$ & $\square$ & $\square$ \\
\hline $\begin{array}{l}\text { Independent } \\
\text { Website }\end{array}$ & $\square$ & $\square$ & $\square$ & $\square$ & $\square$ & $\square$ & $\square$ & $\square$ \\
\hline $\begin{array}{l}\text { Tv- } \\
\text { Program }\end{array}$ & $\square$ & $\square$ & $\square$ & $\square$ & $\square$ & $\square$ & $\square$ & $\square$ \\
\hline Tv-Commercial & $\square$ & $\square$ & $\square$ & $\square$ & $\square$ & $\square$ & $\square$ & $\square$ \\
\hline $\begin{array}{l}\text { Radio- } \\
\text { Program }\end{array}$ & $\square$ & $\square$ & $\square$ & $\square$ & $\square$ & $\square$ & $\square$ & $\square$ \\
\hline $\begin{array}{l}\text { Radio- } \\
\text { Commercial }\end{array}$ & $\square$ & $\square$ & $\square$ & $\square$ & $\square$ & $\square$ & $\square$ & $\square$ \\
\hline $\begin{array}{l}\text { Magazine } \\
\text { Advertisement }\end{array}$ & $\square$ & $\square$ & $\square$ & $\square$ & $\square$ & $\square$ & $\square$ & $\square$ \\
\hline $\begin{array}{l}\text { Magazine } \\
\text { Article }\end{array}$ & $\square$ & $\square$ & $\square$ & $\square$ & $\square$ & $\square$ & $\square$ & $\square$ \\
\hline $\begin{array}{l}\text { Newspaper } \\
\text { Advertisement }\end{array}$ & $\square$ & $\square$ & $\square$ & $\square$ & $\square$ & $\square$ & $\square$ & $\square$ \\
\hline $\begin{array}{l}\text { Newspaper } \\
\text { Article }\end{array}$ & $\square$ & $\square$ & $\square$ & $\square$ & $\square$ & $\square$ & $\square$ & $\square$ \\
\hline $\begin{array}{l}\text { Store } \\
\text { Magazine }\end{array}$ & $\square$ & $\square$ & $\square$ & $\square$ & $\square$ & $\square$ & $\square$ & $\square$ \\
\hline Label & $\square$ & $\square$ & $\square$ & $\square$ & $\square$ & $\square$ & $\square$ & $\square$ \\
\hline Brochure & $\square$ & $\square$ & $\square$ & $\square$ & $\square$ & $\square$ & $\square$ & $\square$ \\
\hline
\end{tabular}


Now please consider the following situation in which you may be looking for product information:

Description of product usage situation

In this situation I find that the media channel should be:...

\begin{tabular}{|cccccccc}
\hline Trustworthy & Detailed & $\begin{array}{l}\text { Time } \\
\text { saving }\end{array}$ & Easy & Personal & Stimulating & Informative & Relaxing \\
\hline$\square$ & $\square$ & $\square$ & $\square$ & $\square$ & $\square$ & $\square$ & $\square$ \\
\hline
\end{tabular}

Which of the following media channels do you consider acceptable for use in the given situation?

\begin{tabular}{l|c}
\hline & $\begin{array}{c}\text { Usage } \\
\text { Situation }\end{array}$ \\
\hline Website & $\square$ \\
Manufacturer & $\square$ \\
Website & $\square$ \\
Cooking & \\
Independent & $\square$ \\
Website & \\
Tv- & $\square$ \\
Program & $\square$ \\
Tv- & $\square$ \\
Commercial & $\square$ \\
Radio- & $\square$ \\
Program & $\square$ \\
Radio- & $\square$ \\
Commercial & \\
Magazine & $\square$ \\
Advertisement & \\
Magazine & $\square$ \\
Article & \\
Newspaper & $\square$ \\
Advertisement & $\square$ \\
Newspaper & $\square$ \\
Article & \\
Store & $\square$ \\
Magazine & $\square$ \\
Label & $\square$ \\
Brochure & $\square$ \\
\hline & \\
\hline
\end{tabular}

